\title{
Renal risk profiling in newly diagnosed hypertensives in an urban population in Nigeria
}

\author{
Aderoju Gbadegesin ${ }^{1}$, Oluyomi Okunola 2 , Olugbenga Ayodele ${ }^{1}$, Fatiu Arogundade ${ }^{2}$, \\ Abubakre Sanusi ${ }^{2}$, Adewale Akinsola ${ }^{2}$
}

1. LadokeAkintola University Teaching Hospital, Osogbo, Nigeria.

2. Obafemi Awolowo University Teaching Hospital, Ile-Ife, Nigeria.

\begin{abstract}
Introduction: Hypertension is a cause and consequence of chronic kidney disease globally. The other factors that work in concert with hypertension to cause CKD are yet to be clearly elucidated. Studies have identified proteinuria, dyslipidemia, obesity, smoking and family history of CKD as renal risk factors. Due to the high morbidity and mortality associated with occurrence of $\mathrm{CKD}$ including the enormous financial burden involved in its management, the knowledge of prevention and understanding of the risk factors for development of $\mathrm{CKD}$ is highly essential. Therefore, Identifying well defined risk factors that display strong graded association with the occurrence and progression of CKD can help in elucidating potential targets for disease modification.

Objective: The aim of this study was to determine the prevalence of renal risk factors and their impact on kidney function in newly diagnosed hypertensive Nigerians.

Methods: This was a case control study of two hundred and fifty newly diagnosed hypertensive Nigerians recruited from two contiguous hospitals in an urban setting in south western Nigeria. Another group of two hundred and fifty apparently healthy age and sex matched normotensive Nigerians in the same community were recruited as controls.

Results: Seventy (28\%) of the newly diagnosed hypertensives had estimated glomerular filtration rate of less than $60 \mathrm{ml} / \mathrm{min}$, while $42.4 \%$ and $18.8 \%$ of the subjects and the controls had microalbuminuria respectively. The newly diagnosed hypertensives had significantly higher prevalence of analgesic use $(86.4 \%$ versus $41.6 \%, \mathrm{p}<0.001)$, alcohol consumption $(20.8 \%$ versus $12 \%$, $\mathrm{p}=0.008)$, use of canned salted food $(18.8 \%$ versus $8.4 \%, \mathrm{p}=0.001)$ and central obesity $(36.1 \%$ versus $26.8 \%, \mathrm{p}=0.025) \mathrm{com}$ pared to controls.

Conclusion: There is a significant occurrence of modifiable renal risk factors in newly diagnosed hypertensives and this offers a platform for instituting preventive strategies in the community.

Keywords: Renal risk, hypertensives, urban population, Nigeria.

DOI: https://dx.doi.org/10.4314/ahs.v19i4.8

Cite as: Gbadegesin A, Okunola O, Ayodele O, Arogundade F, Sanusi A, Akinsola A. Renal risk profiling in newly diagnosed bypertensives in an urban population in Nigeria. Afri Health Sci. 2019;19(4):2863-2873. bttps:// dx.doi.org/10.4314/abs.v19i4.8
\end{abstract}

\section{Introduction}

Hypertension is an important and a major global public health challenge with high prevalence. It affects more people in developing countries and it is projected that by 2025 , almost three- quarters of people with hypertension will be living in developing countries ${ }^{1}$. It is a major cause of chronic kidney disease (CKD) globally and it is associated with increased risk of cardiovascular diseases ${ }^{2}$. It is

\section{Corresponding author: \\ Oluyomi Okunola, \\ Department of Medicine \\ Obafemi Awolowo University Teaching \\ Hospital, Ile-Ife, Nigeria. \\ Email:yok8t@yahoo.com}

also the most prevalent cause of end stage renal disease in sub Saharan Africa with figures ranging from 25-50\% The degree of functional impairment in those who eventually develop CKD is highly variable and this has been attributed to individual variability of risk. The need to also predict those who may eventually develop CKD has further led to the search for risk factors which in concert with hypertension significantly impact on renal function and ultimately leading to ESRD.

Factors implicated as being responsible for CKD progression in hypertensives have been classified into initiating factors such as age, race (African Americans), gender, dyslipidaemias and obesity while the perpetuating factors 
which drive the process include; smoking, anaemia, oligonephroma, level of proteinuria, and the systolic blood pressure level ${ }^{5}$.

In a follow up study of 500 patients with essential hypertension, Pereira reported that proteinuria was found in $42 \%$, while $18 \%$ developed chronic renal insufficiency over a period of time ${ }^{6}$. Cigarette smoking, analgesic consumption in significant quantity amongst others were seen in patients with hypertension induced chronic renal failure in Nigeria in an earlier report by Akinsola et $\mathrm{al}^{7}$. The multiple risk factor interventional trial (MRFIT) study had also reported that the absolute risk of end stage renal disease was highest for those with a baseline blood pressure in the highest category of systolic blood pressure and diastolic blood pressure respectively. The relationship of blood pressure and renal damage was also positive and continuous through blood pressure range ${ }^{8}$. Strategies for prevention of hypertension induced CKD must have a holistic approach based on the identification of renal risk factors that can in concert with hypertension promote the development of $\mathrm{CKD}$, and its sustainability.

Risk profiling is a quantitative analysis of factors accentuating disease progression and its characteristics, the early identification of high risks should therefore form the basis for instituting preventive interventions. This becomes imperative in view of the rising global incidence and prevalence of hypertension induced kidney damage in developing countries. This study was thus carried out to determine the occurrence and pattern of renal risk factors among adult Nigerians with newly diagnosed hypertension and also aimed at detecting the relationship between the risk factors and kidney function.

\section{Methods}

This prospective study was performed at the Ladoke Akintola University Teaching Hospital(LAUTECH), Osogbo, Nigeria and at the General hospital, Osogbo over an 18 month period from Jan 1st 2009 till August 30th, 2010. Ethical approval was obtained for this study from the ethical board of LAUTECH with protocol number LTH/EC/2009/12/56.

Adults aged $\geq 35$ years with newly diagnosed hypertension from General Outpatient units of both centres were enrolled for the study.

\section{Study population}

This consisted of 250 consecutive adults who fulfilled the inclusion criteria for this study and who were newly diagnosed to have hypertension and another 250 age- and sex-matched healthy controls within the same community were also recruited for the study. The participants were $\geq$ 35 years of age, yet to commence antihypertensive drugs, and gave informed consent to be included in the study.

Primary hypertension was defined as systolic blood pressure $\geq 140 \mathrm{mmHg}$ and/ or diastolic pressure $\geq 90 \mathrm{mmHg}$, with the absence of red cells and granular casts from the urine and a protein/creatinine ratio $\leq 2.0$ at baseline.

Patients with biochemical and clinical evidence suggestive of glomerulonephritis were also excluded.

A structured questionnaire was administered seeking information on socio-demographics such as age, sex, marital status and social class as established by income and occupation. History of established renal risk factors such as smoking, alcohol intake, use of salt, use of herbal medicines or remedies, analgesic use, protein intake, family history of hypertension, diabetes, or salient symptomatology of chronic kidney disease which included nocturia, passage of frothy urine and facial swelling amongst others were also obtained.

Alcohol intake was assessed with separate questions about the type, amount of alcohol consumed per week and the duration of alcohol intake prior to study enrolment.

Study participants also answered questions on smoking habits, current smoking status and the average number of cigarettes they smoked per day.The duration of use of herbal medications were also accessed. Questions were also asked concerning use of salts including adding salt to food at table and frequency of consumption of canned salted foods.

A waist circumference of $\geq 102 \mathrm{~cm}$ for male and $\geq 88$ $\mathrm{cm}$ for female were taken as indicative of central/truncal obesity.Urinalysis was done using dipstick (Combi 9®) for the presence of protein, red blood cells, white blood cells, nitrite in urine samples.

Albumin: creatinine (ACR) ratio was done using clinitekR 50 (Bayer Diagnostics urine chemistry analyser, Bayer corporation, Elkhart, USA) for urine samples that were negative for proteinuria (macroproteinuria) with Combi 9 dipsticks.

Microalbuminuria was defined as an ACR of $30 \mathrm{mg} / \mathrm{g}$ to 
$299 \mathrm{mg} / \mathrm{g}$ while macroalbuminuria was defined as an ACR of $\geq 300 \mathrm{mg} / \mathrm{g}$.

Sample for lipid profile, blood glucose and haemoglobin concentration were determined automatically using an auto analyzer machine (SysmexInc, IL 60060, USA). Serum creatinine was measured by a modified kinetic Jaffe reaction. (Alkaline picric acid method, kits from RANDOX Laboratory Ltd. US), and serum electrolytes (sodium, potassium and uric acid) were analysed using flame-photometer.

Diabetes was defined as fasting blood glucose $\geq$ $7.0 \mathrm{mmol} / 1$ (126mg/dl).

The abbreviated Four Variable Modification of Diet in Renal Disease (MDRD) study formulawas used to estimate the glomerular filtration rate; eGFR $(\mathrm{ml} / 1.73 \mathrm{~m} 2)=186 \times \mathrm{PCr}(\mathrm{mg} / \mathrm{dl})-1.154 \times \mathrm{Age}(\mathrm{yrs})$ $-0.203 \times 0.742$ (if female) x 1.210 (if black).

Where eGFR is the estimated glomerular filtration rate, $\mathrm{PCr}$ is the plasma creatinine.

The tests (Haemogram, renal function tests, uric acid, fasting blood sugar and lipid profile) were carried out on all subjects and controls.

Statistical analysis

Analysis was done using Statistical Package for Social Sciences (SPSS) version 15.

Summary statistics such as means, medians and standard deviation were used to summarize quantitative variables while qualitative data were summarized using frequencies and proportions.

The frequency of each risk factor was compared between the hypertensive patients and controls. The correlation between quantitative variables was tested using the Pearson correlation analysis while chi square test was used for two qualitative variables. The t-test and Analysis of
Variance were used to compare means of two and three categories respectively. Bar charts were used to represent qualitative variables.

The risk profile of each patient with newly diagnosed hypertension was determined by combining nine selected risk factors for CKD namely smoking, alcohol intake, herbal concoction use, excessive salt intake, obesity, analgesic use, fasting hyperglycaemia, proteinuria and family history of chronic kidney disease. The number of risk factors was then grouped into 3 categories- 0 - 3 risks, $>3-6$ risks, $>6$ risks representing mild, moderate and severe degrees respectively. The magnitude of the risk factors mild, moderate, or severe (depending on presence of $0-3,>3-6,>6$ risks) was compared between subjects and controls using chi-square test or student t-test for quantitative and qualitative variables respectively.

The independent predictors of outcomes such as GFR were identified using multiple linear regression analysis while the multiple logistic regression was used for dichotomous outcomes such as CKD. For a variable to be entered into the multiple logistic regression model, the $\mathrm{p}$-value on the chi-square tests must have been less than $0.1(10 \%)$. Hence the logistic regression analysis was carried out for predictors which were significantly associated with the outcome at $\mathrm{p}<0.1$ on chi square test. Odd ratios and their 95\% confidence intervals were reported. The level of significance for all tests was $5 \%(\mathrm{p}<0.05)$.

\section{Results}

There were 250 study participants with newly diagnosed hypertension and 250 age and sex matched apparently healthy normotensive controls. The mean age was $55.7 \pm 11.3$ years for the hypertensive patients and $55.2 \pm 12.5$ years for the controls. There were 121 male subjects and 115 male controls respectively. 
Table 1: Comparison of anthropometric indices between hypertensive patients and controls

\begin{tabular}{lccc}
\hline $\begin{array}{l}\text { Anthropometric } \\
\text { measurement }\end{array}$ & $\begin{array}{c}\text { Hypertensives } \\
\text { Mean } \pm \text { SD }\end{array}$ & $\begin{array}{c}\text { Controls } \\
\text { Mean } \pm \text { SD }\end{array}$ & P value \\
\hline Weight (kg) & & & \\
Height (m) & $67.8 \pm 15.0$ & $65.8 \pm 13.3$ & 0.124 \\
Body Surface Area $\left(\mathrm{m}^{2}\right)$ & $1.59 \pm 0.09$ & $1.58 \pm 0.07$ & 0.466 \\
BMI (Kg/m $\left.{ }^{2}\right)$ & $1.69 \pm 0.19$ & $1.67 \pm 0.15$ & 0.142 \\
BMI Class & $27.0 \pm 6.3$ & $26.4 \pm 5.6$ & 0.272 \\
$\quad$ & & & \\
$\quad$ Underweight & $4(1.6)$ & $6(2.4)$ & 0.298 \\
$\quad$ Normal & $99(39.9)$ & $105(42.2)$ & \\
$\quad$ Overweight & $79(31.9)$ & $89(35.7)$ & \\
$\quad$ Obesity & $66(26.6)$ & $49(19.7)$ & \\
Waist Circumference & & & \\
$\quad$ Normal & $159(63.9)$ & $183(73.2)$ & 0.025 \\
$\quad$ Abnormal & $90(36.1)$ & $67(26.8)$ & \\
\hline BMI - Body Mass Index & & &
\end{tabular}

Table 1 shows the means and standard deviation of selected anthropometric indices among the hypertensive patients and controls. There was no statistically significant difference in the mean values of weight $(\mathrm{p}=0.124)$, height $(\mathrm{p}=0.466)$, body mass index $(\mathrm{p}=0.272)$, waist circumference $(\mathrm{p}=0.163)$ and body surface area $(\mathrm{p}=0.142)$ of the hypertensive patients and the controls. When the anthropometric indices were categorized there were significant differences in the waist circumference. A higher proportion of the hypertensive patients had abnormal waist circumference compared to controls $(\mathrm{p}=0.025)$. Body mass index remained non- significant when categorized $(p=0.298)$. 
Table 2: Prevalence of risk factors for CKD amongst hypertensive patients and controls

\begin{tabular}{lccc}
\hline Risk Factors & $\begin{array}{c}\text { Hypertensives } \\
\text { \% }\end{array}$ & $\begin{array}{c}\text { Controls } \\
\text { \% }\end{array}$ & P-value \\
\hline Analgesic Use & 86.4 & 41.6 & $<0.001^{*}$ \\
Smoking & 2.8 & 4.4 & 0.333 \\
Alcohol Use & 20.8 & 12.0 & $0.008^{*}$ \\
Herbal Use & 51.6 & 26.1 & $<0.001^{*}$ \\
Use of salted food & 18.8 & 8.4 & $<0.001^{*}$ \\
Family history of & 7.2 & 8.0 & 0.736 \\
DM & & & \\
Family history of & 35.2 & 10.2 & $<0.001^{*}$ \\
hypertension & & 19.7 & 0.289 \\
Obesity (BMI $\geq$ & 26.6 & & \\
30kg/m & & & \\
& & 26.8 & $0.025^{*}$ \\
Central obesity & 36.1 & 1.2 & $0.021^{*}$ \\
Fasting & 3.3 & & \\
Hyperglycaemia & & 0.7 & $<0.001^{*}$ \\
Macroalbuminuria & 5.6 & 18.8 & $0.001^{*}$ \\
Microalbuminuria & 42.0 & & \\
\hline
\end{tabular}

Key: BMI - Body mass index * = Statistically significant

Table 2 shows that newly diagnosed hypertensives had significantly higher prevalence of analgesic use $(86.4 \% \mathrm{vs}$. $41.6 \%, \mathrm{p}<0.001)$, alcohol use (20.8\% vs. $12 \%, \mathrm{p}=0.008)$, herbal use $(51.6 \%$ vs. $26.1 \%, \mathrm{p}<0.001)$, use of canned salted food $(18.8 \%$ vs. $8.4 \%, \mathrm{p}=0.001)$, and central obesity $(36.1 \%$ vs. $26.8 \%, \mathrm{p}=0.025)$.

The mean serum creatinine among the hypertensive patientswas $91.31 \pm 15.37 \mu \mathrm{mol} / \mathrm{L}$ (range $65-129 \mu \mathrm{mol} / \mathrm{L}$ ) and the mean serum creatinine among the controls was 91.2 $\pm 15.9 \mu \mathrm{mol} / \mathrm{L}$ (range $64-128 \mu \mathrm{mol} / \mathrm{L}$ ). There was however no significant statistical difference in the mean serum creatinine values between the two groups $(t=0.051$, $\mathrm{p}=0.959)$. Table 3 also shows the indicators of renal function compared between newly diagnosed hypertensives and controls. Macroalbuminuria and microalbuminuria were significantly commoner among subjects compared to controls $(\mathrm{p}<0.001)$. Eighty one $(42 \%)$ hypertensive patientscompared to $26(18.8 \%)$ of controls had microalbuminuria, while $14(5.6 \%)$ of the hypertensive patients compared with $1(0.7 \%)$ control had macroalbuminuria. Seventy $(28 \%)$ of the hypertensive patients and ten $(4 \%)$ of the controls had estimated GFR less than $60 \mathrm{mls} /$ $\mathrm{min} / 1.73 \mathrm{~m}^{2}$ respectively.

Table 3: Comparison of indicators of reduced renal function between hypertensive patients and controls.

\begin{tabular}{lccc}
\hline Indicator & $\begin{array}{c}\text { Hypertensives } \\
\mathbf{n ~ ( \% )}\end{array}$ & $\begin{array}{c}\text { Controls } \\
\mathbf{n}(\%)\end{array}$ & P value \\
\hline & & & \\
Serum creatinine $>120(\mu \mathrm{ml} / \mathrm{l})$ & $9(6.0)$ & $3(2.0)$ & 0.079 \\
Microalbuminuria $(\mathrm{mg} / \mathrm{g})$ & $81(42.0)$ & $26(18.8)$ & $<0.001$ \\
Macroalbuminuria $(\mathrm{g} / \mathrm{l})$ & $14(5.6)$ & $1(0.7)$ & $<0.001$ \\
\hline
\end{tabular}




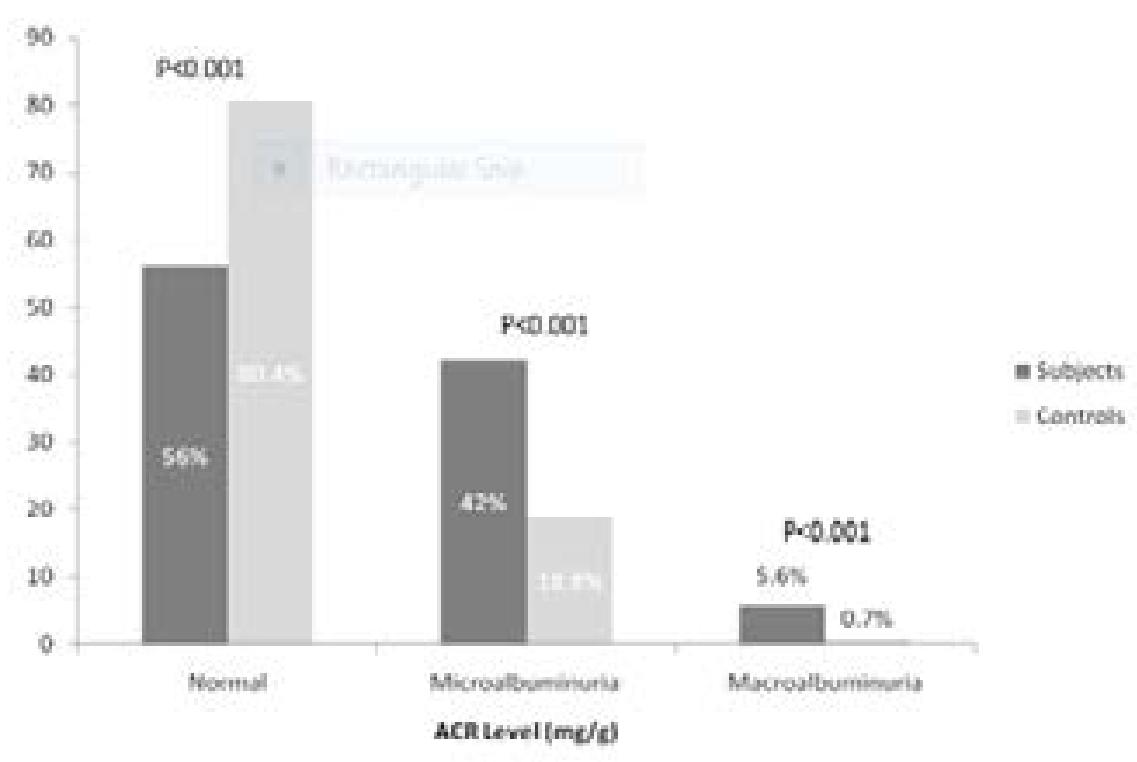

Figure 1

Figure 1 shows the distribution of study population according to albumin- creatinine ratio (ACR). The prevalence of microalbuminuria in the hypertensive patients was $42.4 \%$ compared to $18.8 \%$ in the controls. This was statistically significant $\mathrm{p}<(0.001)$. Macroalbuminuria was also commoner among the hypertensive patients when compared to the controls $(5.6 \%$ vs. $0.7 \%, \mathrm{p}=0.001)$

The output from the logistic regression of impaired kidney function (GFR $<60 \mathrm{ml} / \mathrm{min} / \mathrm{m} 2$ ) on variables is shown in Table 4. After adjusting for the various risk factors identified in this study, the major predictors of impaired kidney function were gender - with females more likely to develop the disease compared to male participants $(\mathrm{OR}=0.244,95 \% \mathrm{CI}=0.108-0.551)$; age which indicates that the hypertensive patientswere more likely to develop $\mathrm{CKD}(\mathrm{OR}=1.064,95 \% \mathrm{CI}=1.043-1.085)$, and fasting hyperglycaemia $(\mathrm{OR}=4.799,95 \% \mathrm{CI}=1.602-$ 14.374)

Table 4: Regression coefficients and confidence intervals from regression of estimated GFR on selected risk factors for CKD among subjects

\begin{tabular}{lccc}
\hline Variable & $\begin{array}{c}\text { Regression } \\
\text { coefficient }\end{array}$ & $\begin{array}{c}\text { 95\% Confidence } \\
\text { interval }\end{array}$ & P value \\
\hline Age & -1.00 & -1.11 to -0.89 & $<0.001^{*}$ \\
Gender (male vs female) & 11.74 & 9.16 to 14.32 & $<0.001^{*}$ \\
Waist circumference & 0.16 & 0.02 to 0.30 & $0.030^{*}$ \\
MABP & 0.22 & -0.002 to 0.44 & 0.052 \\
Smoking & -1.56 & -12.84 to 9.72 & 0.786 \\
BMI & 1.12 & 0.81 to 1.44 & $<0.001^{*}$ \\
Systolic blood pressure & -0.16 & -0.34 to 0.018 & 0.078 \\
Herbal concoction use & -0.893 & -4.370 to 2.585 & 0.614 \\
\hline
\end{tabular}

*Significant at $5 \%$ level 
The comparison of mean eGFR among the risk factor categories is shown in Table 5. The risk factor categories were grouped into 3: less than 3 risks, 3-6 risks and greater than 6 risks. The eGFR decreased with the number of risk factors and the difference was statistically significant ( $p$ <001). Also, the newly diagnosed hypertensives with risk factors have significantly lower mean eGFR when compared with newly diagnosed hypertensive without risk $(59.80 \pm 17.55$ vs $74.68 \pm 20.92 \mathrm{mls} / \mathrm{min}, \mathrm{p}=(0.001)$. Figure 2 shows a significant negative correlation between eGFR and magnitude of risk factors $(r=-0.597, p<$ 0.001).

Table 5: Mean eGFR amongst the risk groups (hypertensive subjects)

\begin{tabular}{llccc}
\hline & Risk Group & $\begin{array}{c}\text { Mean eGFR } \pm \\
\text { SD }\end{array}$ & F & P-value \\
\hline <3risks & $(n=97)$ & $84.6(14.9)$ & 12.182 & $<0.001$ \\
3-6 risks & $(n=101)$ & $77.2(19.9)$ & & \\
$>6$ risks & $(n=52)$ & $68.9(16.8)$ & & \\
\hline
\end{tabular}

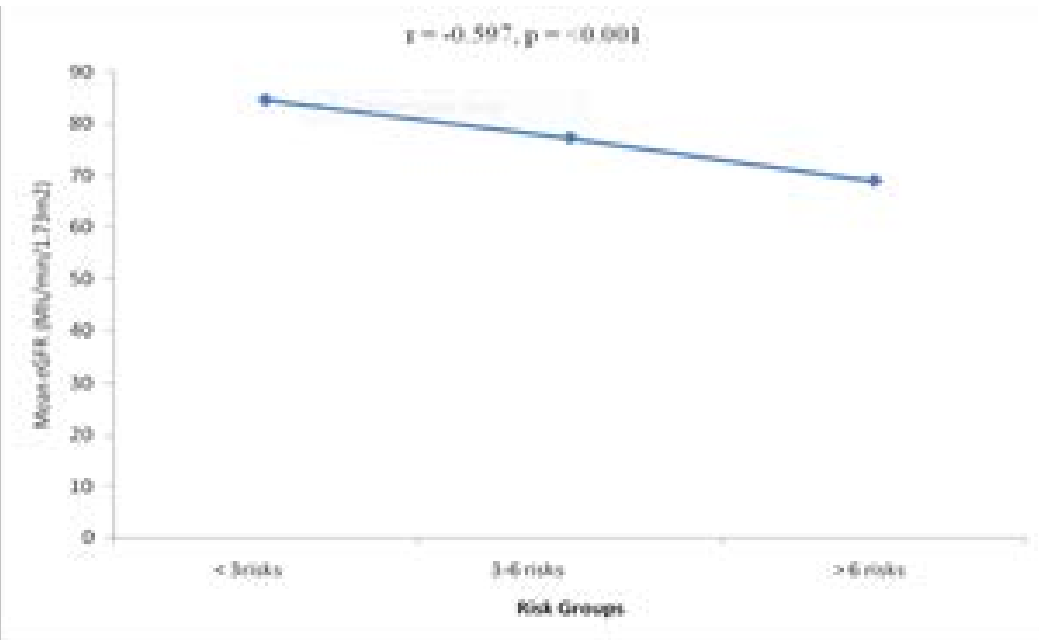

Figure 2 showing the multiple regression analysis of the risk factors on renal function

Nine risk factors namely smoking, alcohol intake, herbal concoction use, excessive salt intake, proteinuria, obesity, fasting hyperglycaemia, analgesic use and family history of CKD were selected in the categorization of the level of $\mathrm{CKD}$ risk. These risk factors were used in classifying patients based on the number of risk factors they possess. A higher number of controls had less than 3 risk factors compared to the hypertensive patients. About 165 $(66.0 \%)$ of the hypertensive patients had greater than 6 risk factors while 42(16.8\%) had between 3-6 risk factors. These were higher when compared to controls. (Table 6)

Table 6: Risk profiling amongst hypertensive patients and controls

\begin{tabular}{lcc}
\hline RISK GROUP & $\begin{array}{c}\text { Frequency in hypertensives } \\
\mathbf{n ~ ( \% )}\end{array}$ & $\begin{array}{c}\text { Frequency in controls } \\
\mathbf{n}(\%)\end{array}$ \\
\hline < 3risk factors & $43(17.2)$ & $177(70.8)$ \\
3-6 risk factors & $42(16.8)$ & $30(12.0)$ \\
>than 6 risk factors & $165(66.0)$ & $43(17.2)$ \\
Total & $250(100)$ & $250(100)$ \\
\hline
\end{tabular}




\section{Discussion}

In this study, renal function was assessed by estimated glomerular filtration rate (GFR) using the Modification of Diet in Renal Disease (MDRD) formula and kidney damage assessed by albuminuria ${ }^{9}$. Seventy $(28 \%)$ of the newly diagnosed hypertensives had estimated GFR < $60 \mathrm{ml} / \mathrm{min}$ and $42.4 \%$ had microalbuminuria, compared with $18.8 \%$ with microalbuminuria amongst the controls. The prevalence of the microalbuminuria in the hypertensive patients in this study is similar to the $45.5 \%$ prevalence reported by Nwankwo et al in newly diagnosed hypertensives ${ }^{10}$. This figure was also higher than figures found by Olatunde et al who reported microalbuminuria of $17.4 \%$ in a similar study done at Ile- Ife, Nigeria ${ }^{11}$. The prevalence observed in the control population in this study is higher than that found by Coresh et al and the Dutch PREVEND study ( $9.3 \%$ and $7.2 \%$ ) respectively ${ }^{12,13}$.

The relatively significant presence of microalbuminuria in this study amongst newly diagnosed hypertensives may indicate early endothelial damage and this portends future glomerular damage and CKD. Specifically, the severity of blood pressure and increased systemic permeability to albumin possibly due to endothelial dysfunction had been found to play an important role in its development. Additional factors such as lipid abnormalities, prothombotic factors, increased activities of RAS and systemic inflammation have also been implicated ${ }^{13,14}$.The goal of drug treatment of hypertension should include amelioration/ reduction of associated microalbuminuria from the onset , particularly among population pre disposed to chronic renal disease.

The prevalence of CKD in this study(as defined by GFR $<60 \mathrm{ml} / \mathrm{min} / 1.73 \mathrm{~m}^{2}$ ) is $28 \%$ in the newly diagnosed hypertensives is similar to what was found in a study by Ayodele et alwho reported a prevalence of $23.1 \%$ among newly diagnosed hypertensive patients ${ }^{15}$. The prevalence was however higher than $4.7 \%, 5.7 \%$ and $8 \%$ reported in NHANES $^{16}$, EPIRCE ${ }^{17}$ and Democratic Republic of Congo $^{18}$. The high prevalence found may not be unconnected to the background hypertension in our subjects which confers higher risk of kidney damage in this population when compared to the other studies which largely consisted of untargeted population.

The mean serum creatinine among the newly diagnosed hypertensives was higher among subjects compared to controls. The prevalence of impaired kidney function using a cut off value of serum creatinine $>120 \mu \mathrm{mol} / \mathrm{L}$ was $6.0 \%$ among the newly diagnosed hypertensives. The Kidneys have strong compensatory function and it may take about $50 \%$ loss of its function before serum creatinine starts to rise. Therefore, measurement of serum creatinine alone may under-diagnose CKD. It is advocated by NKF that renal function be assessed using estimated GFR and other markers of kidney damage which provide a more sensitive representation of kidney function or allows for early diagnosis of CKD for prompt institution of management ${ }^{19}$.

The study found significant association between increasing age and impaired kidney function in both populations studied. As reported in other studies, which shows increasing prevalence of low GFR with age, elderly participants have highest prevalence of CKD and the relationship remains significant even after regression analysis ${ }^{20,21}$. This is in agreement with findings from other studies. Rowe et al and Linderman had reported a natural decline of kidney function with age $\mathrm{e}^{22,23}$. Possible reasons adduced by the latter for this association are reduction in the number of nephron, renal mass and presence of nephrosclerosis in ageing. The mean age of the participants, increased prevalence of risk factors and ethnicity (black race) are likely to have contributed to the higher prevalence in this study than some of the other studies. As impaired kidney function is commoner in the older age group, the recommendation to screen people in this age group would be an important strategy for detection of chronic kidney disease.

It was observed that values suggestive of reduced renal reserve (eGFR $<60 \mathrm{mls} / \mathrm{min}$ ) was commoner in the female $(32.9 \%)$ than male $(20.8 \%)$. Female gender independently predicts CKD in this study. AusDiab ${ }^{20}$, NHANES16 and China21 studies showed significant higher female gender prevalence of CKD. Data regarding the role of gender in determining renal risk in humans are somewhat contradictory. In general, the prevalence of $\mathrm{CKD}$ was greater in male than female regardless of age and also in various ethnic groups. In this study, the female subjects were older, had higher SBP and DBP (although these values were not statistically significant) and these findings may explain the higher prevalence of eGFR $<60 \mathrm{mls} / \mathrm{min}$ and albuminuria in females compared to males. However, many studies have shown higher prevalence of ESRD in males than females ${ }^{22,23,24}$. 
Obesity represents a state of excess storage of body fat and could be defined as an excess body weight for height. With prolonged obesity, there is resultant further impairment of renal-pressure natriuresis, leading to a more severe hypertension and a gradual loss of kidney function ${ }^{25}$. Aryee et al in a case control study involving 241 participants noted that hypertensives with chronic kidney disease had higher anthropometric indices, it was observed that body adiposity index and abdominal volume index were associated with corresponding incremental changes in the bloodpressure ${ }^{26}$. In this study, a significant number of study participants (newly diagnosed hypertensives) had central obesity.

Smoking as a risk factor to renal damage was also noted in this study, as it may contribute to renal damage via sympathetic nervous activation, sustained hypertension via promotion of renal atherosclerosis and effects on endothelial functions ${ }^{27}$. Generally it shortens the interval from microalbuminuria to overt nephropathy and accelerates progression of nephropathy and loss of glomerular filtration rates ${ }^{27}$.

The habitual consumption of alcohol was seen in $20.8 \%$ of the subjects. It causes an increase in sympathetic activity, stimulation of the renin angiotensin-aldosterone system and an increase of intracellular calcium levels with a subsequent increase in vascular reactivity ${ }^{29}$. However these seems to be speculative.

Excessive salt consumption was seen in $18.8 \%$ of the subjects compared with $8.4 \%$ among the controls $(\mathrm{P}<$ 0.05). In patients with hypertension, an increase in salt intake often increases the GFR, vascular resistance, calculated intraglomerular capillary pressure and protein excretion $^{30}$. Studies such as DASH and INTERSALT have all suggested a reduction in salt quantities to reduce cardiovascular morbidity. The KDIGO recommends a sodium intake of less than $90 \mathrm{mmol} / \mathrm{day}(2 \mathrm{~g})$ which corresponds to $5 \mathrm{~g}$ of sodium chloride .

Analgesic consumption was also significant among 86.4\% of the subjects compared with the controls. In Nigeria the pattern of analgesic consumption and its contribution to renal disease is not fully known. Abioye-kuteyi found a prevalence of $74.7 \%$ in a rural area consisting of unskilled workers31. Hypertension, pre-existing renal disease are known risk factors for renal failure after ingestion of NSAIDS ${ }^{32}$.
Chronic analgesic nephropathy is a slowly progressive renal disease resulting from daily use for many years of mixture containing at least two analgesics (e.g aspirin, paracetamol, phenacetin) and caffeine, codeine, and/or barbiturates, which may lead to psychological dependence and overuse. The cumulative dose of analgesics required to cause renal impairment is about $4 \mathrm{~kg}$ over 2 years ${ }^{31}$. When the risk factors were grouped into three: less than 3(mild risk), 3-6 risk (moderate risks), $\geq 6$ risk (high risks), there was significant difference in the prevalence of renal risk in the newly diagnosed hypertensives when compared to the controls. Occurrence of multiple risks was associated with reduction in renal function, there was an inverse relationship between occurrence of multiple risks and decrease in eGFR. Also, the mean eGFR was found to be higher in subjects with no added risk compared to those with risk(s). The above findings may be explained by the multi-hit hypothesis which states that multi-factors interact to overcome renal reserve and provoke progressive nephron loss ${ }^{33}$. The magnitude of the risk factors in newly diagnosed hypertensives therefore plays an important role in the subsequent reduction in renal reserve.

\section{Conclusion}

The study reports a high prevalence of modifiable renal risk factors. These include analgesic abuse, herbal concoction and obesity amongst the newly diagnosed hypertensives. Markers suggestive of early impairment of kidney function as evident by microalbuminuria and reduced GFR were also present in a sizeable number of patients and they stand a higher risk of faster disease progression and of having cardiovascular complications. This finding underscores the need to improve the awareness of hypertension in the population since this will lead to early detection.

Analgesic abuse and undefined herbal remedy usage should be discouraged. In conclusion, methods that could be used to stem down the risk factors especially in developing countries and indeed globally is through continuous promotion and advocacy of healthy behaviours and habits via education and awareness.

\section{Financial support and sponsorship}

Nil.

\section{Conflicts of interest}

The authors have no conflict of interest to declare concerning this research work. 


\section{References}

1. Kearney PM, Whelton M, Reynolds K, Muntner P, Whelton PK, He J . Global burden of hypertension: analysis of worldwide data. Lancet 2005; 365:217-223

2. McCullough PA, Jurkovitch CT, Pergola PE, McGill JB, Brown NW, Collins AJ et al. Independent components of chronic kidney disease as a cardiovascular risk state: results from the Kidney Early Evaluation Program (KEEP). Arch Intern Med 2007; 167:1122-1129.

3. Okunola O, Akinsola A and Ayodele O. Kidney diseases in Africa: Aetiological considerations, peculiarities and burden. Afr J Med Med. 2012;41:119-133

4. Osafo C, Mate-Kole M, Affram K, Adu D. Prevalence of chronic kidney disease in hypertensive patients in Ghana. Ren. Fail. 2011; 33(4) 388-92.

5. Taal MW and Brenner BM. Predicting initiation and progression of chronic kidney disease: developing renal risk scores. Kidney Int 2006;70:1694-1705

6. Pereira G: Hypertensive vascular disease: description and natural history. J. Chronic Dis 1955; 1:33 - 42.

7. Akinsola A and Adelekun TA. Hypertension induced chronic renal failure: clinical features, management and prognosis. WAJM, 1998; 17(2): 104-108

8. Klag MJ, Whelton PK, Randall BL, Neaton JD, Brancati FL, Ford CE et al. Blood pressure and end stage renal disease in men. N Engl J Med 1996, 334; 13-18

9. Kidney Disease Improving Global Outcomes (KDIGO) CKD work Group 2012. Clinical practice guideline for the evaluation and management of chronic kidney disease. Kidney Int Supplement 2013;3(1):1-150

10. Nwankwo EA, Wudiri WW. Akinsola A: Risk factor for development of chronic kidney disease among Nigerians with essential hypertension. J. Med. Sci 2007; 7(1): 579-584

11. Olatunde LO, Arogundade FA, Balogun MO. Microalbuminuria and its clinical correlates in essential hypertension. NigJ Health Sci, 2002; 2: 25-29.

12. Coresh J, Stevens LA. Kidney function estimating equations: where do we stand? Curr Opin Nephrol Hypertens 2006; 15:276-284.

13. Verhave JC, Gansevoort RT, Hillege HL, Bakker SJ, De Zeeuw D, De Jong PE; PREVEND Study Group: An elevated urinary albumin excretion predicts de novo development of renal function impairment in the general population. Kidney Int Suppl. 2004; 66: S18 -S21.

14. Giuseppe D'Amico and Claudio Bazzi. Pathophysiology of proteinuria. Kidney. Int. 2003:63:809-205
15. Ayodele OE, Egbewale BE andAlebiosu CO. Kidney function and clinical correlates in newly diagnosed hypertensives attending a University Teaching Hospital in Southwest Nigeria. African J. Med. med.sc. 2007; 36 : 95 101

16. United States Renal Data System. USRDS 2002 Annual Data Report. 2002; Atlas of End-Stage Renal Disease in the United States, Bethesda, National Institutes of Health, National Institute of Diabetes and Digestive and Kidney Diseases, 2002.

17. Otero A, Gayoso P. Epidemiology of chronic renal disease in the Galician population: Results of the pilot Spanish EPIRCE study. Kidney Int. 2005; 68: S16 - S19 18. Sumaili EK, Krzesinski JM, Zinga CV: Prevalence of chronic kidney disease in Kinshasa: Results of a pilot study from the democratic republic of Congo. Nephrol Dial Transport 2009; 24:117-122

19. National Kidney Foundation K/DOQI Clinical Practice Guidelines for Chronic Kidney Disease: Evaluation, Classification and Stratification. Am J Kidney Dis 2002; 39 (2 Suppl 1): S1 - S266.

20. Chadban SJ, Briganti EM, Kerr PG, Dunstan DW, Welborn TA, Zimmet PZ et al. Prevalence of chronic kidney damage in Australian adults. The AusDiab Kidney Study. J. Am Soc Nephrol. 2003; 14(7 suppl 2): S131-S138. 21. Hallan SI, Coresh J, Astor BC, Asberg A, Powe NR, Romundstad S et al: International comparison of the relationship of chronic kidney disease prevalence and ESRD risk J. Am SocNephrol 2006:17:2275-2284

22. Rowe JW, Andres R, Tobin JD, Norris AH, Shock $\mathrm{NW}$ et al. The effect of ageing in creatinine clearance in men: a cross sectional and longitudinal study. J. Gerontol 1976; 31(2):155-163.

23. Lindeman RD, Tobin J, Shock NW: Longitudinal studies on the rate of decline in renal function with age. J. Am Geriatr Soc 1985; 33: 278 - 285.

24. Eriksen BO, Ingebretsen OC: The progression of chronic kidney disease: a 10 year population based study of the effects of gender and age. Kidney Int 2006; 69:375-382.

25. Hall JE. Pathophysiology of obesity hypertension. Curr Hypertens Rep 2000;2:139-147

26. Aryee C, OwireduWK,Osei-yeboahJ,Owusu-Dabo E, Laing E et al. An analysis of anthropometric indicators and modifiable lifestyle parameters associated with hypertensive nephropathy. Int. J. Hypertens. 2016. Doi. org/10.1155/2016/6598921 
27. Ritz E, Benck U, Franek E, Keller C, Seyfarth M, Clorious J. Effect of smoking on renal heamodynamics in healthy volunteers and in patients with glomerular disease. J Am Soc Nephrol 1998;(10):1798-804

28. Orth SR, Ogata H, Ritz E. Smoking and the kidney. Nephrol Dial Transplant. 2000;15:1509-1511

29. Savdie E, Grosslight GM, Adena MA. Relation of alcohol and cigarette consumption to blood pressure and serum creatinine levels. J chronic Dis 1984;37:617-23

30. Mallamaci F, Leonardis D, Bellizzi V. Does high salt intake cause hyperfiltration in patients with essential hypertension. J Hum Hypertens 1996;10:157-161

31. Abioye-Kuteyi EA, Akinsola A, Ezeoma IT. Renal disease: The need for community-based screening in rural Nigeria. Afr J Med Pract 1999; 6(5):198-201

32. De Broe ME, Elseviers MM: Analgesic nephropathy. N Engl J Med 338: 446-452, 1998

33. Kasiske BL, Ma JZ, Louis TA, Swan SK : Longterm effects of reduced renal mass in humans. Kidney Int. 1995; 48(3): 814 - 819. 